\title{
THE DESIGN OF AN EFFICIENT PRIVATE INDUSTRY
}

Philippe Jehiel

CERAS-ENPC and

University College London

\author{
Benny Moldovanu \\ University of Bonn
}

\begin{abstract}
Government-sponsored auctions for production rights (e.g., license auctions, privatizations, etc.) shape the industry structure. Are there mechanisms that induce an efficient industry structure (at least when there are no positive costs to public funds)? The answer is "no" whenever firms have private information about both fixed and marginal costs. Our analysis also suggests that the second-best industry may either be more competitive or more monopolistic than the first-best one. These insights are in sharp contrast with the ones obtained for models where firms have one-dimensional private information, thus requiring more delicate policy recommendations. (JEL: D43, D45, D82, L1)
\end{abstract}

\section{Introduction}

A government that privatizes a public firm or that sells licenses for production rights affects the market structure of the corresponding industry. What is the best selling strategy for the government? Should the government use auctions, or should it use other, more elaborate mechanisms?

Most economists argue that auctions are particularly desirable in those contexts where the government has little idea about the value of the goods for sale since auctions induce a revelation of valuations through a natural competition mechanism. But, simple auction mechanisms (like the ones practitioners mostly have in mind) are problematic in those contexts in which the auction shapes the ensuing market structure. ${ }^{1}$

In this paper we ask whether there exists mechanisms (simple or not) that induce an efficient market structure. There are two firms competing for the right to produce (or to acquire a privatized firm). The government can either produce itself, or it can award the right to produce to one of the firms, or to both. An important element in the model is that the competing firms have private

E-mail addresses: Jehiel: jehiel@enpc.fr; Moldovanu: mold@uni-bonn.de

1. In particular, flexible auction formats that allow the firms themselves to affect the ensuing market structure may be used to induce more monopolistic market structures, which is undesirable from the consumers' viewpoint (see Jehiel and Moldovanu 2000; 2003). 
information that bears both on the fixed cost and the marginal cost associated with future production. ${ }^{2}$ Thus, private information is multidimensional.

Unlike most of the literature on regulation (see Laffont and Tirole 1993) we abstract away from the costs of public funds (these inevitably give rise to transferability issues). Thus, we wish to emphasize here that difficulties arise even if frictions due to such costs are absent. ${ }^{3}$ Hence we assume that utility is transferable: The efficiency criterion is defined by the sum of utilities of all agents (including the profits of the firms and the consumer surplus), and transfers do not play a role since their sum (over all participants) adds up to zero.

The previously sketched model closely follows Dana and Spier (1994) who have analyzed government auctions with an endogenous market structure under the assumptions that (1) firms have one-dimensional private information (either on fixed cost or on marginal cost, but not both) and (2) there are positive costs to public funds, that is, the government values revenue more than it values consumer or producer surplus. In their model, the first-best can always be achieved if the shadow cost of public funds is equal to one (as assumed here). The main finding of Dana and Spier (see also Auriol and Laffont (1992) and McGuire and Riordan (1995) for similar insights) is that the second-best market structure is more biased toward sole sourcing than the first-best whenever there are positive costs to public funds. ${ }^{4}$ The intuition is that biasing the market structure toward sole sourcing is a way to reduce the informational rents of the more efficient firms (since pretending to be less efficient also reduces the chance of being a monopolist).

At first glance, it seems that a procedure based on the well-known VickreyClarke-Groves (VCG) intuition can be used to induce an efficient outcome in our setup in which costs of public funds are absent. But, this argument ignores that VCG insight applies only to the private values paradigm (e.g., firms ex ante have the necessary information needed to calculate their own expected profits in the various market structure configurations). But the private values paradigm does not apply here: For example, in order to assess the profit in a duopoly configuration, a firm needs to know, say, the marginal cost of the other licensed firm, a piece of information which is usually not available ex ante. The present set-up is thus one of interdependent values.

2. If there were several different kinds of production rights, the structure of the private information could be even more complex.

3. It is also unclear to us how large these costs are in practice. Any theory finely relying on these costs must make the case that they are significant.

4. McGuire and Riordan (1995) obtain this conclusion only when the costs of public funds are not too large, which is presumably a valid assumption in most applications. 
The VCG insight can be in fact generalized to interdependent values if agents have one-dimensional signals. ${ }^{5}$ But, as Jehiel and Moldovanu (2001) have shown, the generalization breaks down if agents have multidimensional signals. ${ }^{6}$ The consequence for the present model is that any mechanism ${ }^{7}$ will induce an inefficient market structure for some realizations of the parameters.

We also suggest that the optimal second-best industry structure may either be more competitive or more monopolistic than the first-best, depending on the distribution of incomplete information and payoff specifications.

The rest of the paper is organized as follows. In Section 2 we present the formal model, which is similar to the one analyzed by Dana and Spier (1994), except for the multidimensional private information and the absence of costs to public funds. In Section 3 we state our main result. In Section 4 we provide a further discussion about the links to the existing literature.

\section{The Model}

Our model parallels that of Dana and Spier (1994) with two essential differences to be outlined next.

For simplicity, we assume that there are only two ${ }^{8}$ firms (or bidders). Each bidder $i$ privately observes a two-dimensional signal $\theta_{i}=\left(F_{i}, c_{i}\right)$ that reflects its cost structure: $F_{i}$ is a fixed cost and $c_{i}$ is the marginal cost. In contrast, Dana and Spier assume that the private information is one-dimensional (the authors distinguish according to whether this one-dimensional private information is the fixed cost or the marginal cost, but they do not allow the private information to bear on both).

The signals $\theta_{1}$ and $\theta_{2}$ are independently distributed on $[\underline{F}, \bar{F}] \times[\underline{c}, \bar{c}]$ with continuously differentiable density functions. ${ }^{9}$ We let $\pi^{m, i}\left(\theta_{i}\right)$ denote firm $i$ 's profit if it is awarded a sole production right (monopoly/sole source). This profit function is independent of $\theta_{-i}$ because in this case only the cost structure of firm $i$ determines its ensuing profit. We let $\pi^{d, i}\left(\theta_{1}, \theta_{2}\right)$ denote firm $i$ 's profit if both firms are awarded production rights (duopoly/dual-source). This profit function

5. See Jehiel and Moldovanu (2001) for a social choice setup allowing also for allocative externalities, and Maskin (1992), and Dasgupta and Maskin (2000) for simple auction setups.

6. Maskin (1992) exhibits a one-object auction example where bidders have two-dimensional private signals about the object and he shows that no efficient mechanism exists. The reason for Maskin's result is however different from that in the present paper: Bidders care only about one alternative (where they get the object), but have a two-dimensional signal about it. But any mechanism can only condition on a one-dimensional sufficient statistic.

7. We implicitly assume here that the mechanism cannot be made contingent on information that is revealed at a later stage (e.g., future profits). See the discussion on this point in the last section.

8. Our insights obviously carry over to more general settings.

9. We do not need to assume that the distributions are symmetric. 
generally depends on $\theta_{-i}$, at least through $c_{-i}$ (for example, think of Cournot competition in a market for a homogenous good). Finally, we assume that a firm earns zero profits if it is not awarded a production right. ${ }^{10}$

Consumer surplus depends on the market structure and on the cost structure of the firms involved. Accordingly, we let $S^{m, i}\left(\theta_{i}\right)$ denote the consumer surplus when firm $i$ is the sole producer, and let $S^{d}\left(\theta_{1}, \theta_{2}\right)$ denote this surplus when both firms produce. ${ }^{11}$

The government has the option to produce itself with cost parameter $\theta_{g}=$ $\left(F_{g}, c_{g}\right)$, assumed to be common knowledge.

Overall, there are four possible alternatives referred to as $k=1,2, d, g$ :

- Sole-source (firm $i=1,2)$ with associated welfare $W^{i}\left(\theta_{i}\right)=S^{m, i}\left(\theta_{i}\right)+$ $\pi^{m, i}\left(\theta_{i}\right)$

- Dual-source with associated welfare $W^{d}\left(\theta_{1}, \theta_{2}\right)=S^{d}\left(\theta_{1}, \theta_{2}\right)+\pi^{d, 1}\left(\theta_{1}, \theta_{2}\right)$ $+\pi^{d, 2}\left(\theta_{1}, \theta_{2}\right)$

- Government production with associated welfare $W^{g}\left(\theta_{g}\right)$ (this term already includes consumer surplus in this alternative)

We assume that the social planner's objective is to maximize expected welfare which is given by:

$$
W=E\left[\sum_{i} \pi_{i}+S\right]
$$

where $S$ denotes the consumer surplus and $\pi_{i}$ the profit of firm $i$. Possible transfer payments $t_{i}$ from bidder $i$ to the government do not enter the social planner's criterion because we assume that there are no costs of public funds.

In contrast, Dana and Spier (1994) assume that the government maximizes

$$
W=E\left[\sum_{i} \pi_{i}+S+(\lambda-1) \sum_{i} t_{i}\right]
$$

where $\lambda>1$ represents the shadow cost of public funds. This is another essential difference (other than dimensionality) between their paper and ours. ${ }^{12}$

By the revelation principle, there is no loss of generality in restricting attention to direct revelation mechanisms where agents report truthfully in

10. We make this assumption to keep as close as possible to the model of Dana and Spier (1994). In a number of applications this is a rather restrictive assumption. For example, if one of the firms is an incumbent who produces in a related market, the assumption is not met. In such cases, the participation constraint is itself affected by the mechanism (see Jehiel, Moldovanu, and Stacchetti, 1996, 1999).

11. Like Dana and Spier (1994), we do not assume that the designer has to elicit the information about the demand function. Clearly, our insights carry over to the more plausible setting in which the designer needs not have private information about demand.

12. In Dana and Spier's model, if $\lambda=1$ the designer can obtain the first-best. 
equilibrium. Such mechanisms can be described as follows: Each bidder $i$ makes an announcement $\hat{\theta}_{i}$ about his two-dimensional signal. Based on the profile of announcements, $\left(\hat{\theta}_{i}, \hat{\theta}_{-i}\right)$, the designer chooses an allocation $p^{k}\left(\hat{\theta}_{i}, \hat{\theta}_{-i}\right)$ and a transfer $t_{i}\left(\hat{\theta}_{i}, \hat{\theta}_{-i}\right)$, where for each profile of reports $\left(\hat{\theta}_{1}, \hat{\theta}_{2}\right), p^{k}\left(\hat{\theta}_{i}, \hat{\theta}_{-i}\right)$ is the probability that alternative $k$ is chosen, and $t_{i}\left(\hat{\theta}_{i}, \hat{\theta}_{-i}\right)$ is the transfer from firm $i$ to the designer.

Let

$$
\Pi_{i}\left(\hat{\theta}_{i} \mid \theta_{i}\right)=E_{\theta_{-i}}\left[p^{i}\left(\hat{\theta}_{i}, \theta_{-i}\right) \pi^{m, i}\left(\theta_{i}, \theta_{-i}\right)+p^{d}\left(\hat{\theta}_{i}, \theta_{-i}\right) \pi^{d, i}\left(\theta_{i}, \theta_{-i}\right)-t_{i}\left(\hat{\theta}_{i}, \theta_{-i}\right)\right]
$$

Truthful revelation requires that:

$$
\text { For all } \theta_{i}, \quad \hat{\theta}_{i}, \Pi_{i}\left(\theta_{i} \mid \theta_{i}\right) \geq \Pi_{i}\left(\hat{\theta}_{i} \mid \theta_{i}\right)
$$

The participation constraints require that:

$$
\text { For all } \theta_{i}, \quad \Pi_{i}\left(\theta_{i} \mid \theta_{i}\right) \geq 0
$$

The designer's optimization problem is

$$
\max _{t_{-} i p^{k}} E_{\theta_{l}, \theta_{2}}\left[\sum_{k=1,2, d, g} p^{k}\left(\theta_{i}, \theta_{-i}\right) W^{k}(\theta)\right]
$$

subject to the incentive constraints (1) and to the participation constraint (2).

Because we assume that there are no costs to public funds, it is readily verified that the participation constraints are never binding in our context. To see this, observe that the welfare criterion as well as the incentive constraints are unaffected if all transfers $t_{i}\left(\hat{\theta}_{i}, \hat{\theta}_{-i}\right)$ are reduced by a fixed term $T$. By choosing $T$ sufficiently large we can get rid of the participation constraints. Thus, the designer's problem reduces to maximizing (3) subject to the incentive constraints (1).

\section{The Main Result}

It is rather difficult to characterize the solution to the program defined in Section 2. However, a simple point can be addressed. The first-best industry structure requires choosing a market structure $k^{*}\left(\theta_{i}, \theta_{-i}\right) \in \arg \max _{k} W^{k}\left(\theta_{i}, \theta_{-i}\right)$ for each realization of $\left(\theta_{i}, \theta_{-i}\right)$. Clearly, if such an allocation rule were implementable it would be the solution to the designer's problem. But, as the following proposition shows, such an allocation rule cannot be implemented:

Proposition 1. For generic profit functions $\pi_{i}^{m, i}\left(\theta_{i}\right)$ and $\pi_{i}^{d}\left(\theta_{i}, \theta_{-i}\right)$ and for generic distributions of signals, any implementable industry structure is inefficient with positive probability. 
The fundamental reason behind the above result is that the incentive constraints impose much more stringent conditions when the type space is multidimensional than when it is one-dimensional. While in the one-dimensional case, incentive constraints generally translate into a monotonicity conditions on the interim allocation rule (see for example the classical analysis in Myerson 1981), in the multidimensional case an additional integrability constraint appears. This constraint forces some identities that cannot hold generically for the efficient allocation rule. To understand this point, let $V_{i}\left(\theta_{i}\right)=$ $\Pi_{i}\left(\theta_{i} \mid \theta_{i}\right)=\max _{\hat{\theta}_{i}} \Pi_{i}\left(\hat{\theta}_{i} \mid \theta_{i}\right)$ denote the equilibrium interim expected utility of bidder $i$ with type $\theta_{i}=\left(F_{i}, c_{i}\right)$. Under mild assumptions, ${ }^{13}$ the envelope theorem can be invoked to infer that: ${ }^{14}$

$$
\begin{gathered}
\frac{\partial V_{i}\left(\theta_{i}\right)}{\partial F_{i}} \equiv E_{\theta-i}\left[p^{i}(\theta) \frac{\partial \pi^{m, i}\left(\theta_{i}\right)}{\partial F_{i}}+p^{d}(\theta) \frac{\partial \pi^{d, i}(\theta)}{\partial F_{i}}\right] \\
\frac{\partial V_{i}\left(\theta_{i}\right)}{\partial c_{i}} \equiv E_{\theta-i}\left[p^{i}(\theta) \frac{\partial \pi^{m, i}\left(\theta_{i}\right)}{\partial c_{i}}+p^{d}(\theta) \frac{\partial \pi^{d, i}(\theta)}{\partial c_{i}}\right]
\end{gathered}
$$

But, at any point of differentiability, $V_{i}$ must have equal cross-derivatives:

$$
\frac{\partial}{\partial c_{i}}\left[\frac{\partial V_{i}\left(\theta_{i}\right)}{\partial F_{i}}\right] \equiv \frac{\partial}{\partial F_{i}}\left[\frac{\partial V_{i}\left(\theta_{i}\right)}{\partial c_{i}}\right]
$$

This means that

$$
\begin{aligned}
& \frac{\partial}{\partial c_{i}} E_{\theta-i}\left[p^{i}(\theta) \frac{\partial \pi^{m, i}\left(\theta_{i}\right)}{\partial F_{i}}+p^{d}(\theta) \frac{\partial \pi^{d, i}(\theta)}{\partial F_{i}}\right] \\
&=\frac{\partial}{\partial F_{i}} E_{\theta-i}\left[p^{i}(\theta) \frac{\partial \pi^{m, i}\left(\theta_{i}\right)}{\partial c_{i}}+p^{d}(\theta) \frac{\partial \pi^{d, i}(\theta)}{\partial c_{i}}\right]
\end{aligned}
$$

The identity in (6) imposes a relation that involves the allocation rule $p^{k}(\theta)$ and the payoff functions $\pi^{m, i}\left(\theta_{i}\right), \pi^{d, i}(\theta)$. Note that the efficient allocation rule is completely determined except on measure zero of events where the designer is indifferent between two or more alternatives, and that it clearly depends on the consumer surplus induced by each market structure. Thus, for generic values of the profit functions, there is no hope that the efficient allocation rule be compatible with identity (6) since that identity is independent of the consumer surplus. The impossibility result follows.

To get more intuition for the result, it is instructive to consider the simpler case where only Firm 1 has private information. That is, the type $\theta_{2}^{*}$ of Firm 2 is assumed to be common knowledge. Any mechanism sets a fixed transfer $t^{k}$ for

13. See Milgrom and Segal (2002) for the weakening of the required standard assumptions.

14. Note that $\partial \pi^{m, i}\left(\theta_{i}\right) / \partial F_{i}=\partial \pi^{d, i}(\theta) / \partial F_{i}=-1$ if $F_{i}$ is a separable fixed cost. 
each possible alternative, and lets Firm 1 choose his preferred alternative given these transfers. ${ }^{15}$

Consider types $\theta_{1}$ on the boundary between the regions where sole production by Firm 1 and dual production are efficient. This boundary is defined by the following system:

$$
\begin{gathered}
S^{m, 1}\left(\theta_{1}\right)+\pi^{m, 1}\left(\theta_{1}\right)=S^{d}\left(\theta_{1}, \theta_{2}^{*}\right)+\pi^{d, 1}\left(\theta_{1}, \theta_{2}^{*}\right)+\pi^{d, 2}\left(\theta_{1}, \theta_{2}^{*}\right) \\
S^{m, 1}\left(\theta_{1}\right)+\pi^{m, 1}\left(\theta_{1}\right) \geq S^{m, 2}\left(\theta_{2}^{*}\right)+\pi^{m, 2}\left(\theta_{1}^{*}\right)
\end{gathered}
$$

Equation (7) is equivalent to

$$
\pi^{m, 1}\left(\theta_{1}\right)-\pi^{d, 1}\left(\theta_{1}, \theta_{2}^{*}\right)=S^{d}\left(\theta_{1}, \theta_{2}^{*}\right)-S^{m, 1}\left(\theta_{1}\right)+\pi^{d, 2}\left(\theta_{1}, \theta_{2}^{*}\right)
$$

On the other hand, for the efficient industry structure to be implementable, any type $\theta_{1}$ on the boundary must be indifferent between sole and dual production:

$$
\pi^{m, 1}\left(\theta_{1}\right)-t^{1}=\pi^{d, 1}\left(\theta_{1}, \theta_{2}^{*}\right)-t^{d}
$$

In other words, there should be a constant $\Delta t=t^{1}-t^{d}$ such that

$$
\pi^{m, 1}\left(\theta_{1}\right)-\pi^{d, 1}\left(\theta_{1}, \theta_{2}^{*}\right)=\Delta t
$$

The impossibility result follows by noting that equations (9) and (11) cannot be compatible with each other for arbitrary functions $S^{d}\left(\theta_{1}, \theta_{2}^{*}\right), S^{m, 1}\left(\theta_{1}\right)$, and $\pi^{d, 2}\left(\theta_{1}, \theta_{2}^{*}\right)$.

Figure 1 depicts the corresponding partition of the $\left(F_{1}, c_{1}\right)$ type space in areas where each possible market structure is efficient. ${ }^{16}$

\section{Discussion}

Even if there are no costs to public funds, the first-best cannot be achieved in our model. It is then natural to ask how the second-best market structure is biased relative to the first-best.

As in most multidimensional incentive problems, it is very hard to characterize the second-best, and more work is needed to derive sharper characterizations. However, there is no reason why the market structure should be biased toward sole sourcing (a result that was obtained in the simpler one-dimensional models). ${ }^{17}$

15. This is a version of the so-called taxation principle, and is the mere translation of the incentive constraints in the principal-agent problem.

16. To simplify, we assumed here that only alternatives $k=1,2$ and $d$ can be efficient.

17. In the multidimensional setup it is not a priori clear which incentive constraints are binding (and it is thus even less clear how to bias the allocation rule in order to relax the incentive constraints). 


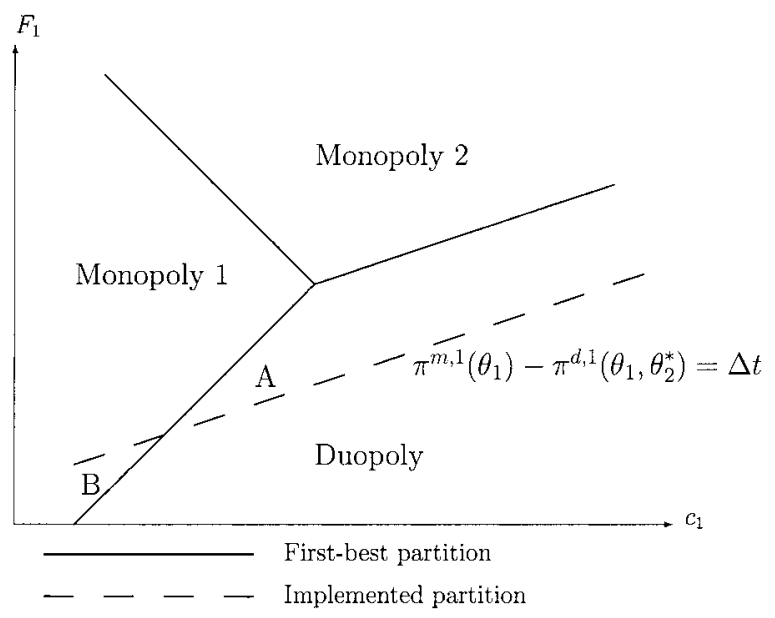

FIGURE 1. Marker structure partition.

For example, consider the case considered at the end of the previous section where only Firm 1 has private information. Recall that any feasible mechanism sets a transfer $t^{k}$ for each possible alternative, and then lets Firm 1 choose her preferred alternative given these transfers.

As Figure 1 illustrates, for any values of $t^{k}$, the implemented market structure is biased toward sole sourcing for types $\theta_{1}$ lying in region $A$ and it is biased toward dual sourcing for types $\theta_{1}$ lying in region $B$. The aggregate bias will obviously depend on functions governing the distribution of type $\theta_{1}$, and cannot generally be one-sided as in the one-dimensional models considered in the earlier literature.

Implicitly, we have considered so far static one-shot mechanisms in which the allocation rule and the transfers are decided at the same time. As long as bidders' information remains the same throughout a possibly sequential mechanism, our impossibility result applies. ${ }^{18}$ Things change however if bidders acquire further information during the interaction. In a recent paper, Mezzetti (2002) considers an interdependent valuation setup in which bidders get to observe (for free) their payoff in the chosen social alternative before monetary transfers are made. He observes that the efficient allocation can be implemented through an ingenious two-stage mechanism: In Stage 1 bidders reveal their private information which is solely used to implement the efficient alternative; in Stage 2, each bidder is asked to report his payoff (assumed to be known to the bidder by then) and transfers are then made according to the Vickrey-

18. Because, roughly speaking, the incentive constraints apply to the normal form representation of a possibly multiperiod mechanism. 
Clarke-Groves rule, that is, each bidder receives a transfer that is, up to a constant, equal to the sum of other bidders' reported payoffs. ${ }^{19}$

We wish to point out here that bidders' incentives to reveal truthfully their payoffs in Stage 2 of Mezzetti's mechanism are virtually nonexistent since bidders are completely indifferent as to which payoff to report: the alternative has been chosen already, and their transfer only depends on the reports of others. This suggests that such mechanisms are not appealing from a practical viewpoint. $^{20}$ This finding should be contrasted with the original insight of the Vickrey-Clarke-Groves mechanisms where the incentives to report truthfully are, except in degenerate cases, strictly positive (think of the second-price auction in a private value setting; there truth telling is forced by the still to be resolved uncertainty about who will be the actual winner).

Finally, note that schemes in which transfers are postponed until all information is available (think about a license auction where the license fees are payed after the profits from operation have been already realized) are also very sensitive to renegotiation pressures and moral hazard. Most practitioners are well aware of these dangers.

\section{References}

Auriol, Emanuelle and Jean-Jacques Laffont (1992). "Regulation by Duopoly." Journal of Economics and Management Strategy, 1, 507-533.

Dana, James and Kathy Spier (1994). "Designing a Private Industry: Government Auctions with Endogenous Market Structure." Journal of Public Economics, 53, 127-147.

Dasgupta, Partha and Eric Maskin (2000). "Efficient Auctions." Quarterly Journal of Economics, 115, 341-388.

Jehiel, Philippe and Benny Moldovanu (2000). "License Auctions and Market Structure." Working paper, University of Mannheim and University College London.

Jehiel, Philippe and Benny Moldovanu (2001). "Efficient Design with Interdependent Values." Econometrica, 69, 1237-1259.

Jehiel, Philippe, and Benny Moldovanu (2003). "An Economic Perspective on Auctions." Economic Policy, 36, 269-308.

Jehiel, Philippe, Benny Moldovanu, and Ennio Stacchetti (1996). "How Not to Sell Nuclear Weapons." American Economic Review, 86, 814-829.

Jehiel, Philippe, Benny Moldovanu, and Ennio Stacchetti (1999). "Multidimensional Mechanism Design for Auctions with Externalities." Journal of Economic Theory, 85, 258 294.

Laffont, Jean-Jacques and Jean Tirole (1993). A Theory of Incentives in Procurement and Regulation. MIT Press.

Maskin, Eric (1992). "Auctions and Privatization.” In Privatization: Symposium in Honor of Herbert Giersch, edited by H. Siebert, 115-136. Tuebingen: J. C. B. Mohr.

19. Since bidders know their own payoff this is very much like a private value setting, and efficiency can be accordingly achieved.

20. It might even be argued that malicious bidders have incentives to distort their reports in order to hurt competitors. 
McGuire, Thomas and Michael Riordan (1995). "Incomplete Information and Optimal Market Structure: Public Purchases from Private Providers." Journal of Public Economics, 56, 125-141.

Mezzetti, Claudio (2002). "Auction Design with Interdependent Valuations: The Generalized Revelation Principle, Efficiency, Full Surplus Extraction and Information Acquisition." Working paper, University of North Carolina.

Milgrom, Paul and Ilya Segal (2002). "Envelope Theorems for Arbitrary Choice Sets." Econometrica, 70, 583-601.

Myerson, R. B. (1981). "Optimal Auction Design.” Mathematics of Operations Research 6, $58-73$. 